\title{
El pasaje del estado y el derecho a la postmodernidad ${ }^{1}$
}

\author{
Passage of the State and the Law to Postmodernity
}

Eduardo Rodríguez Martinez ${ }^{2}$

Fecha de Recepción: 22 de mayo de 2016

Fecha de Aprobación: 7 de junio de 2016

\section{Resumen}

El presente artículo pretende explorar la génesis social que fue dando origen a la implementación y constitución de lo que en nuestros días se conoce como el campo neoliberal y neoinstitucional como fórmulas novedosas de regulación global de las relaciones sociales de producción del capitalismo globalizado. La hipótesis que se defiende en estas líneas es que estos campos son el fruto del agotamiento que sufrió el modelo Taylorista-Fordista-Keynesiano, propio del denominado Estado de Bienestar, debido a la naturaleza de las luchas sociales que se desarrollaron dentro de ese contexto. El objetivo general que se quiere mostrar en la argumentación es que el tipo de Derecho asociado al Estado de Bienestar está íntimamente asociado a las tesis que sobre el mismo desarrolló Max Weber, pero que en nuestros días ese tipo de racionalidad cada vez más tiende a carecer de sentido. El artículo quiere introducirse en la discusión contemporánea sobre el carácter y significado del Derecho en la sociedad del

1 Este artículo es resultado del proyecto de investigación titulado "El Pasaje del Estado y el Derecho a la Posmodernidad" que se desarrolla dentro del marco institucional de la Facultad de Derecho de la Universidad La Gran Colombia. Este proyecto se desarrolla desde el ańo 2014. El proyecto de investigación pertenece al grupo de investigación denominado Teoría del Derecho, la Justicia y la Política, categorizado por Colciencias.

2 Abogado, mágister en Sociología, doctor en Sociología Jurídica e Instituciones Políticas de la Universidad Externado de Colombia. Profesor de la Maestría en Derecho de la Universidad la Gran Colombia. Profesor Asociado de la Facultad de Derecho de la Universidad Nacional de Colombia. Correo electrónico: jrodriguezm2@ hotmail.com 
capitalismo globalizado para inscribirse en el plano teórico y político de su naturaleza de regulación y subordinación o de su naturaleza emancipatoria en el seno del movimiento social.

Palabras clave: Sociología del Derecho, Derecho Económico, Crisis del Derecho, Monismo Jurídico, Instituciones Formales e Informales, Movimientos Sociales.

\begin{abstract}
The present article seeks to explore the social genesis that he/she came giving origin to the implementation and constitution of what is known as the neoliberal field and neoinstitucional like novel formulas of global regulation of the social relationships of production of the capitalism globalization in our days. The hypothesis that defends in these lines is that these fields are the fruit of the exhaustion that suffered the Taylorista-Fordista-Keynesian pattern characteristic of the compound number State of Well-being, due to the nature of the social fights that you/they were developed inside that context. The general objective that one wants to show in the argument is that the type of Right associated to the State of Well-being is intimately associated to the theses that it has more than enough the same one Max Weber it developed but that in our days that type of rationality more and more it spreads to lack sense. The article wants to be introduced in the contemporary discussion on the character and meaning of the Right in the society of the capitalism globalization to register in the theoretical and political plane of its regulation nature and subordination or of its nature emancipator in the breast of the social movement.
\end{abstract}

Keywords: Sociologic Law, Economic Right, Crisis of the Right, Juridical Monism, Formal and Informal Institutions, Social Movements.

\title{
Objetivos.
}

\section{General.}

- Entender la significación social y política de las transformaciones de los ordenamientos jurídicos desde la perspectiva de los estudios económicos del derecho. 


\section{Específicos.}

- Analizar los supuestos teóricos de las conceptualizaciones que se apoyan en los denominados estudios económicos del derecho.

- Realizar un estudio crítico sobre los límites estructurales de estas conceptualizaciones sobre el derecho.

- Estudiar el nivel de asociación y complementariedad entre las dinámicas de legitimación del derecho basadas desde estas perspectivas y las nuevas categorías políticas contemporáneas.

\section{Problema de investigación.}

Para efectos de esta investigación, se formuló el siguiente problema de investigación: ¿Las tendencias de la globalización del derecho constituyen un paradigma orientado por los estudios económicos del derecho?

\section{Introducción.}

Hoy por hoy se han venido desarrollando diferentes y novedosas conceptualizaciones alrededor del Derecho, en particular medida en su énfasis de su papel e impacto con las estructuras económicas. Se puede decir que se viene realizando estudios de lo que se conoce con el nombre de Derecho Económico para seńalar las formas de regulación jurídica del mundo de la economía. Sin embargo, contemporáneamente viene abriéndose camino una reflexión todavía más novedosa que podría señalarse con el nombre de Derecho y Desarrollo Económico, que pretende examinar el impacto de las instituciones jurídicas en todo el universo de la economía. El objetivo de estos estudios es investigar cómo el Derecho interactúa como variable exógena (y, por qué no, como variable endógena) dentro de los componentes constitutivos de las relaciones económicas de un país, permitiendo que el crecimiento económico sea posible o impulsado. El Derecho no solamente como regulador del mundo económico sino como instancia determinante en las tendencias de crecimiento y desarrollo 
económico dentro de una sociedad. Estos estudios han sido la base central de las experiencias y estudios de las denominadas corrientes neoinstitucionalistas (Coase, 1994; North, 2001; Williamson, 1989), que vienen pretendiendo darle una significación no ortodoxa al papel del derecho y la justicia, particularmente como estructura determinante del desarrollo sostenible y del crecimiento económico de los diferentes países (Burgos, 2006; Burgos, 2006i).

El objetivo del presente trabajo pretende esquemáticamente entender cómo la aparición de este campo teórico ${ }^{3}$ se corresponde plenamente con un modelo de reestructuración de las relaciones sociales de producción, dentro de la denominada sociedad red (Castells, 1999), que dentro de nuestro marco conceptual constituye el pasaje de la transición entre la fase de acumulación fordista y la construcción de un nuevo orden social, que para algunos constituye una nueva fase de la acumulación de capital. Este pasaje no puede ser leído como un simple modelo económico, ni jurídico, ni político, sino como una redefinición profunda de las relaciones sociales de producción que compromete igualmente las formas de producción de la propiedad (Moncayo, 2004; Rodríguez, 2008). Es dentro de este contexto que el problema de investigación de este ensayo quiere estudiar cómo las tendencias de la globalización del derecho constituyen un paradigma orientado por los estudios económicos del derecho.

Por tales motivos, el texto quisiera trasegar a través de un breve recuento por los dilemas del Fordismo y de su Estado de Bienestar, que aquí lo caracterizamos más que Estado Plan, como Estado Crisis (Altamira, 2006). Con esta caracterización queremos proseguir con la anticipación o la lectura contextualizada de la obra de Friedman $(1985,1980)$ que anticipada y provocadoramente (conservadoramente) parece advertir los límites de la regulación Keynesiana frente a la dinámica de los movimientos sociales, queriendo advertir desde muy temprano los dilemas que el Fordismo podía suscitar al orden capitalista y su constitución democrática.

Si es que podemos aproximarnos a una descripción de una metodología para la elaboración de este artículo, podríamos sintetizarla diciendo que se trata de un trabajo analítico deductivo, teórico crítico y basado, en algunos aspectos en la práctica teó-

3 El campoal que nos referimos está constituido por las corrientes teóricas denominadas neoliberales, neoinstitucionales y los estudios económicos del Derecho que para efectos las consideramos un campo paradigmático. 
rica. Este trabajo parte del paradigma teórico iniciado por Pashukanis en el campo del Derecho y de la denominada escuela de la lógica del capital. A partir de estos paradigmas teóricos conceptuales, hicimos la lectura crítica de los textos asociados con la escuela denominada de estudios económicos del derecho.

En este sentido, se realizó un trabajo de análisis de textos, dentro de un ejercicio comprensivo de los posibles impactos de las tendencias contemporáneas de renovación del derecho, sobre fuentes basadas más en los aportes del conocimiento científico y técnico, que en la racionalidad inherente o propia de los sistemas legales.

\section{Análisis Socio Político del Contexto Fordista de donde surge los Campos Neoliberales y Neoinstitucionales.}

Los estudios sobre el fordismo nacen de manera más sistemática desde los trabajos de autores franceses e ingleses aglutinados o conocidos bajo el nombre de la Escuela de la Regulación (Coriat, 1979; Aglietta, 1987; Jessop, 1999; Lipietz, 1992; Boyer, 1992) quienes, intentando hacer un análisis y desarrollo de los trabajos de Marx (1977), con relación a la época de la manufactura, de la subsunción formal y de la vigencia del plusvalor absoluto, advierten un pasaje cualitativamente distinto con la llegada o instalación de la gran industria, de la subsunción real y de la vigencia del plusvalor relativo.

Dentro del período del plusvalor absoluto se consolida la denominada economía política (clásica y neoclásica) propia del Estado del Capitalismo Liberal que dio origen a la obra más conocida de Marx, en su forma de Crítica de la Economía Política. De manera muy reduccionista, se puede caracterizar a esta manera (Rodríguez, 2012) algunos rasgos constitutivos de este período, a saber:

1. Aquí es donde opera el nacimiento de la fábrica. Las relaciones capitalistas de producción son muy poco extendidas gracias a que el proceso de proletarización está precariamente desarrollado y organizado. El trabajo todavía se encuentra atado a sus antiguos oficios y, por tanto, conserva su relación directa con las condiciones objetivas del proceso de producción sea tierra, herramientas, bienes, etc. 
2. La contribución de la relación salarial es precaria gracias a que el trabajo asalariado es escaso y la participación del estado se destina más a la provisión de ciertas condiciones generales de la producción como son el sistema de transporte, de comunicaciones e infraestructura urbana. La organización social encuentra todavía protección frente a las tendencias de monetización de las relaciones sociales de producción, razón por la cual la organización de los sistemas de crédito son incipientes. La base técnica sobre la que reposa la producción capitalista limita el radio de acción del capital y de la constitución y organización de un mercado amplio. Esta igualmente condiciona y limita el grado de concentración y centralización del capital.

3. Dentro de este periodo asistimos a la consolidación del Estado Liberal y a la ideología del laissez faire, bases conceptuales y políticas de constitución del mercado. En este sentido el mercado se desarrolla a través de la formación abstracta del individuo y de la sociedad civil que inauguran el dualismo: sociedad civil-estado. Dentro de esta fase, dado el incipiente desarrollo de las relaciones mercantiles el principio del laissez faire no puede ser igualmente válido para todos. La sociedad civil todavía no adquiere una naturaleza universal por estar presente dentro de ella formas de organización de la producción no capitalista. De allí que la intervención estatal adquiera una naturaleza ambigua. La racionalidad formal del derecho se desarrolla a través de la codificación del derecho civil, la organización de los Códigos comerciales y el desarrollo de las sociedades comerciales como garantes de la libertad de acción. El derecho privado constituye la piedra angular de la regulación jurídica en donde la racionalidad del contrato, la autonomía de la voluntad privada y la función supletoria del derecho positivo (y, por tanto, del Estado) constituyen los principios de su lógica de desarrollo.

4. Sin embargo, las potencialidades de la lógica del derecho privado de constituirse en equivalente general de la propiedad individual presenta límites:

a. Los principios del Estado, el mercado y de la comunidad no logran adquirir su estado de equilibrio por la no correspondencia entre los principios de la solidaridad y la identidad, de la justicia y al autonomía y entre la igualdad y la libertad (Sousa Santos, 1988). 
b. La situación precedente se explica por la existencia de formas de propiedad basada sobre los lazos de la comunidad que no permite el desarrollo pleno del principio de individualización consagrado en el derecho. Es por esta razón que el derecho aparece en muchos casos como un privilegio y en otros aparece como una tarea que debe impulsar el Estado para conseguir su vigencia y universalización.

c. Los dilemas asociados con los derechos y garantías civiles y políticas (los asuntos relacionados con la ciudadanía) constituyen el campo de las controversias y las disputas sociales en la medida en que no se han desarrollado plenamente las bases para una organización racional del mercado de trabajo.

Este período fue "superado" gracias a la revolución tecnológica generada desde la naciente ciencia moderna de la Administración Empresarial, iniciada con los trabajos pioneros de Taylor (1970) y con la innovación introducida por Henry Ford, con la banda de montaje. El primero sistematizó a través de la técnica de los Tiempos y Movimientos el fraccionamiento y especialización del trabajo vivo y racionalizó las labores puramente manuales de las de concepción y comando de la producción. El segundo construyendo su famoso Ford $\mathrm{T}$ dio inicio a la línea y banda de montaje, dando esta ecuación la introducción del Cronómetro como medida del valor del trabajo y la productividad (Coriat, 1979). La sociedad Fordista, entonces, se caracterizó por la producción en masa de mercancías desvalorizadas que requería para su validación o realización la ampliación del mercado.

La crisis del 29 constituye el primer campanazo de alerta para el capital de las debilidades de este modelo que Friedman (1985) trata de explicar posteriormente como un asunto no relacionado con el equilibrio perfecto que genera la mano invisible sino con asuntos relacionados con la mala intervención de la Reserva Federal y su entendimiento de la crisis.

A pesar de sus explicaciones, el proceso de intervencionismo del Estado gana terreno gracias a las "generosas" explicaciones y justificaciones de Keynes que culminan con el nacimiento del Estado de Bienestar. El fordismo se blinda, entonces, dentro del trípode del Taylorismo-Fordismo-Bienestar. La demanda efectiva y el pleno empleo 
se constituyen en el horizonte de la nueva forma de la regulación (Roldosky, 1978; Grossmann, 1979; Rodríguez, 2002).

Antes de proseguir con este recuento es necesario hacer una breve digresión. ¿Cómo aparece la forma jurídica en este escenario? Hemos insistido en que en esta época del plusvalor relativo requiere la estandarización del producto a nivel del proceso de trabajo (la división técnica de este). Pero al unísono desde el horizonte de la división social del mismo es necesario desarrollar una nueva significación de la forma jurídica que permita otorgarle al sistema legal un doble carácter: de un lado, propiciar un mecanismo objetivo desde donde se pueda apreciar materialmente cuando nacen las obligaciones ${ }^{4}$ de los sujetos que participan dentro de este nuevo escenario $y$, de otro lado, es menester juridizar las relaciones sociales para que el proceso anterior sea posible. Este doble movimiento lo entiendo con una lectura en argolla entre el nacimiento de la Teoría Pura del Derecho (Kelsen, 2005) y la Teoría del Derecho de Weber (1977), que confluyen en los siguientes puntos esenciales, a saber:

1. En el monopolio legítimo de la violencia (Weber) o la violencia socialmente organizada (Kelsen).

2. El derecho tiene un papel trascendental en el principio de autoridad (Kelsen) o en la forma de la dominación legal racional -legitimación-(Weber).

3. El comando del nuevo orden jurídico-político ya no puede devenir del derecho privado (el mercado) sino del Estado de Derecho Constitucional en su forma de Monismo Jurídico. Esta forma de derecho es constitutivo del orden social del fordismo.

Esta digresión sirve para establecer cómo en esta época el fordismo no puede ser considerado como un proyecto económico, tecnológico o jurídico, sino un paradigma tecno-estructural (Rodríguez, 2008), un orden global de la producción social en donde el sistema jurídico es parte constitutiva de ese mismo orden (Moncayo, 1990; Rodríguez, 1990). De la misma manera, las instituciones correspondientes a

4 El concepto de Kelsen de “imputación”. 
ese paradigma. El "institucionalismo Fordista” ya fue suficientemente caracterizado por Michael Foucault como el pasaje de la sociedad disciplinaria.

\section{La Relación Salarial y Las Normas de Consumo.}

Es necesario aquí examinar más de cerca el doble componente de la relación salarial surgida en el período que estamos comentando. Inicialmente, se analizará el salario monetario o directo. Anteriormente, el salario directo era bajo y precario, pero gracias a la existencia de la economía doméstica (Meillassoux, 1981), que guardaba cierta autonomía relativa con relación a la producción, se lograba una articulación de formas productivas sustentadas sobre una división sexual del trabajo, en donde la mujer se encargaba de múltiples oficios, entre otros la educación y crianza de los hijos. Esta situación del trabajo de la economía doméstica no era validada como trabajo socialmente necesario y dio necesariamente origen a las denuncias sobre la existencia de la sociedad patriarcal (Weinbaum, 1984).

Con el impulso y dinamismo del comando Fordista su expansión se ve en una paradoja: de un lado proteger esas formas de economía doméstica y de familia, consanguínea extensa y luego consanguínea nuclear, como una forma de abaratar el componente variable del capital. Pero, de otro lado, la necesidad de incorporar a nuevos contingentes poblaciones a la producción moderna del fordismo exigía el ingreso de la mujer al mercado laboral. Posteriormente este proceso se va a conocer como la "feminación del mercado laboral", que corresponde con esta necesidad del fordismo (Rodríguez, 1996).

El salario monetario tiende a individualizarse generando una degradación de la familia nuclear al vaciarla de sus funciones productivas. El trabajo que ejecutaba la mujer relacionado con la educación, alimentación, cuidado del espacio familiar, crianza de los hijos, etc. tiende a desaparecer al convertirse en una institución vacía. Hoy por hoy la mujer participa, aunque cada día menos, de estas tareas, pero sigue denunciando en muchos casos el agotamiento producido por la extensión de su jornada laboral caracterizada por la categoría de la doble o triple jornada a la que se ve sometida. Más allá de las nuevas condiciones del trabajo "moderno" de la mujer, se asiste lentamente a una crisis de la estructura familiar y del derecho de familia que no logra cumplir 
plenamente con las necesidades que exige la reproducción de la fuerza de trabajo en los términos y necesidades de productividad requeridas por la relación salarial.

En otros términos, la reproducción obrera debe hacerse o realizarse con los mismos niveles de eficiencia como se produce en el taller. Es aquí donde aparece el Estado de Bienestar con la asistencia pública y el salario no monetario o indirecto. La intervención pública aparece como una respuesta o contra tendencia a la crisis propiciada por el descenso de la tasa general de beneficio. Su participación, por tanto, se entremezcla como un dispositivo de asegurar la reproducción global de la fuerza laboral de conformidad a la relación salarial y las normas de consumo que permitan el abaratamiento de la parte variable del capital. Más que esto. Comenzamos asistir a un desplazamiento, en donde la reproducción social (el consumo) lentamente tiende a vincularse al proceso inmediato de producción como un escenario propicio para la obtención de plusvalor.

Las políticas del bienestar se centran, entonces, en la provisión de los elementos variables de la reproducción, como es el caso de la vivienda, la salud, la educación, la recreación, los servicios públicos domiciliarios, etc., proveídos por el Estado como productor y como parte de los fines esenciales del Estado. En el orden constitucional, en muchos lugares se introducen reformas constitucionales, animadas por las tesis del jurista y sociólogo León Duguit, sobre la función social de la propiedad que pretende afectar vía tributación (impuestos directos) a la propiedad para cumplir esta nueva naturaleza esencial del Estado.

A su turno, podemos advertir que si bien la familia no desaparece plenamente, ella va transitando hacia una transición desde el derecho privado hacia el derecho público en la medida en que el derecho de familia y su jurisdicción, apelando al cuidado de los niños y los derechos de las mujeres y la denominada violencia intrafamiliar, va perdiendo su intimidad relativa y su regulación se traslada a un asunto de interés público. El derecho de familia transita entre una encrucijada que va de su reconocimiento como derecho privado y como derecho público. Estas transformaciones del Estado y del Derecho han sido caracterizadas como el transito del derecho privado hacia la administrativización del derecho, como derecho público. 


\section{La Edad De oro del Capital.}

Con la irrupción del Keynesianismo y el Estado de Bienestar se comenzaron a oír las primeras voces neoliberales (de naturaleza conservadora) como fueron las de Von Hayek (1986), que consistieron en un discurso poco académico y anticomunista en donde veía la planeación y regulación keynesiana como asimilada a las de sus enemigos de la guerra fría. A pesar de ello, la inevitable expansión del modelo Fordista se fortaleció en la posguerra, con el Plan Marshall, y podríamos decir con Hobsbawm (1995) que se asistió a la Edad de Oro del capital Fordista.

Es dentro de este período que se producen los trabajos de Friedman $(1980,1985)$, que de manera anticipada, y que tendremos más adelante oportunidad de presentar mejor sus tesis, advierte las debilidades del Estado de Bienestar.

Para poder entenderlas creo necesario presentar sumariamente algunos acontecimientos del capitalismo de ese período (décadas del 50 y 60) que a nuestro juicio constituyen las señales mas visibles que obligarán mas tarde a abandonar el bienestar. De manera sintética y muy general podríamos señalar las siguientes, a saber:

1. A pesar de que el Estado de Bienestar fue pensado desde la demanda efectiva y el pleno empleo, es decir, como un proyecto expansivo que desde el centro tenía capacidades de universalización, su despliegue inicial se centraba en el obrero masa, es decir para los trabajadores propiamente activos o vinculados al taller y no para los parados o población excedentaria. Estos últimos, se esperaba, deberían entrar paulatinamente dentro del circuito del fordismo en la medida en que la expansión del modelo fuera posible gracias a la aceleración de la acumulación. De cualquier manera, y a pesar de las diferencias del bienestar en Estados Unidos y Europa (Navarro, 1977), se generaron políticas públicas como el subsidio a los parados como un mecanismo de integración social mientras hacían la fila para el ingreso al taller.

2. Para comienzos de los años 70 el modelo comienza a mostrar síntomas de agotamiento. No es nuestra intención caracterizar estos síntomas. Pero muchos estuvieron asociados no por contradicciones internas del modelo sino directamente asociados con la dinámica del movimiento obrero y la aparición 
de los nuevos movimientos sociales (Offe, 1988). El agotamiento de la fuerza laboral fue muy rápida y generó fatiga y enfermedades entre los trabajadores (Dejorurs, 1987), ausentismo, idas al médico, retrasos, pérdida de la "pertenencia" institucional, etc. El desgaste acelerado de la fuerza laboral tuvo impactos negativos para los servicios del bienestar que para algunos, aunque por muchas otras razones terminaron requiriendo fondos públicos, cada vez más adicionales, generando lo que se conoce como la Crisis Fiscal del Estado (O’Connor, 1981).

3. Desde la perspectiva de la masificación y estandarización de la producción, es decir, la producción masificada de mercancías desvalorizadas, la "opulencia” del bienestar fue generando estrategias de resistencia obrera ya no en el terreno del taller sino en la esfera del consumo, principalmente en sus luchas por el salario no monetario. El obrero masa sindicalizado no solo reivindicaba "a trabajo igual, salario igual" frente a la medición taylorista del salario sino, desde fuera del taller, se pedía ampliación del salario no monetario. Los "parados", los nuevos movimientos sociales (feministas, ecologistas, negros, migrantes, etc.) enfilaron sus luchas por el reconocimiento al acceso de los bienes del bienestar en una perspectiva que reclamaba igualdad de acceso y reconocimiento de la diferencia. En este nuevo terreno de la confrontación, que expresa un sentido de resistencia a la homogenización del obrero masa, parece haber un rechazo a su constitución como "clase obrera Fordista" y una apertura a la constitución de la no clase, a través del apelo o aparición de la multiculturalidad (Rodríguez, 2008).

4. La lucha por los derechos multiculturales, sin duda, rompen frontalmente con la estructura del Estado de Derecho Constitucional y su Monismo Jurídico al tener lentamente que reconocer las autonomías surgidas en las luchas por el reconocimiento, por la pluralidad de derechos o por la aparición del Pluralismo Jurídico (Palacio, 1993; Rodríguez,1991).

5. Esta situación de emancipación ha sido reseñada por el pensamiento conservador de Bell (1996) como contradicciones culturales del capitalismo para señalar el decaimiento de la ética del trabajo por otra "ética" basada en la cultura hedonista, del placer, la satisfacción, etc., generada por el Rock, el Hipismo, 
los alucinógenos, en fin, por un abandono de la sociedad al proyecto de organización Fordista del trabajo.

6. Estos movimientos sociales estuvieron asociados con las protestas y secuelas de mayo del 68, el movimiento anti-Vietnam, la producción y constitución de nuevas subjetividades que desafiaban al sujeto de derecho de la teoría jurídica, al camino de construcción de formas alternativas de vida como fueron las comunas, tanto rurales como urbanas, en fin, un camino en donde el obrero masa pretendió recuperar su propia valorización obrera construyendo caminos o propuestas de producción de la vida por fuera de las instituciones sociales Fordista.

7. La construcción de nuevas subjetividades partieron por reconocer en los "Bienes Culturales" como propios o constitutivos de la nueva identidad colectiva. Se aproximaron hacia la construcción de un sujeto primeramente social y secundariamente hacia una individuación de esa subjetividad que se reclamaba como comunal. El territorio de la producción subjetiva, entonces, se planteó ya no en el terreno de las instituciones ni de las tecnologías, sino que reposó en los cuerpos comunitarios de sus actores, como expresión de su propia libertad. El territorio de la subjetividad fue su propio cuerpo.

8. Bell ve en este nuevo terreno de la confrontación, de la emancipación del sujeto, como un decaimiento de la cultura tradicional norteamericana, la del puritanismo, y una exaltación a una reformulación del sentido de la vida sin horizonte de sentido en el "trabajo" que sin duda castró los potenciales que anteriormente habían ofrecido el arte y la literatura (los críticos y el mercado) en la generación de valores agregados, de nuevas significaciones para el desarrollo de nuevos productos e innovaciones aplicables, entre otras, para la gran industria cultural tan poderosa en su época.

9. Desde otro lado, Friedman encara tempranamente este contexto y en vez de asumir una postura negativa observa como este dinamismo del movimiento social si bien es dañino para la democracia, por el igualitarismo del cual está preñado, aprovecha la oportunidad para volver a releer los nuevos conceptos de libertad que encierra el movimiento social y eufemísticamente los lee como 
un regreso a los principios de la libertad clásica de mercado. Es decir, el intuye que es posible reinventar la libertad de mercado desde el mismo terreno que los nuevos movimientos sociales habían querido desafiarla. Se trata, para él, de mercantilizar la libertad de los sujetos sociales del bienestar a través del desmonte del bienestar, base material desde donde estos se apoyaban. Las mujeres, los negros, los migrantes, etc. pueden continuar con su libertad pero vendiéndola como trabajadores en la industria de las artes o de cualquier oficio. Por esta razón, Friedman animadamente nos recuerda como el pan que se vende desdibuja la huella del trabajo del trabajador negro que produce el trigo, de la mujer subordinada a la doble o triple jornada, etc. El trabajo coagulado en el pan y expuesto en las vitrinas solo nos muestra el espectáculo neoliberal de la libertad de elegir y del capitalismo y libertad, que en otro aparte tendremos sucintamente oportunidad de presentar.

10. Frente a los movimientos sociales es necesario hacer algunas consideraciones. En primer lugar, éstos lucharon por el acceso al salario no monetario pero en un sentido diferente para el cual éste fue construido. Los movimientos sociales pedían acceso a la "justicia" del Bienestar pero como mecanismo para proteger y crecer en su autonomía (que Friedman la entiende monopolio) constitutiva de su nueva subjetividad, como forma de participar en la riqueza socialmente producida pero hacia la construcción de un proyecto "alternativo" de sociedad.

El acceso a la justicia debe entenderse como un acceso contra hegemónico, no dirigido a transitar por la justicia o reconocimiento individual que les podría conceder el sistema jurisdiccional sino su propia concepción de justicia, basada en los procesos de constitución de sus fragmentadas subjetividades a partir de sus propias luchas por su reconocimiento, no solo estatal sino fundamentalmente cimentada en su autonomía colectiva, su pluralidad comunal. En segundo lugar, los nuevos movimientos sociales penetraron igualmente el terreno del taller y los viejos espacios de organización clásica del obrero masa (sindicatos) que necesariamente impulsó el nivel de reivindicaciones de los trabajadores de la producción inmediata hacia modalidades de tipo no solo economicista o material sino hacia formas o "demandas" inmateriales que a nuestro juicio terminaron por cuestionar frontalmente la disciplina del taller y sus instituciones. 
11. Este nivel de análisis nos sirve para avanzar hacia algunas breves consideraciones en el terreno del sistema legal y del derecho. Empecemos diciendo que las teorías liberales de la justicia (Rodríguez, 2012) que se sitúan a finales de los 70 denotan el impacto de este contexto en el terreno del derecho. En primer lugar, podemos decir que el esfuerzo y el recurso del velo de ignorancia de Rawls (1995) no logró ser suficiente para encontrar un espacio de medida a la inconmensurabilidad de derechos que estuvieron en juego por tratarse, a nuestro juicio, de derechos por fuera del Sujeto de Derecho, hacia formas anticipatorios de formas de propiedad anteriormente sugeridas.

En segundo lugar, los derechos en serio de Dworkin (1989) lo que evidenció en su debate con Hart (1988) fue la crisis del derecho positivo de corte Kelseniano, propio de la racionalización jurídica del fordismo. De allí puede juzgarse cómo las normas de textura abierta hacia los principios y valores (¿bases conceptuales del nuevo constitucionalismo?) nos llevan nuevamente a la concepción liberal tradicional de democracia, de la libertad e igualdad del mercado abandonando, como se deduce, las bases conceptuales y jurídicas del bienestar, los derechos económicos sociales y culturales, y las promesas o perspectivas utópicas de la realización de una forma particular de entender los Derechos Humanos. Estos filósofos y juristas del derecho contemporáneo expresan la crisis del Monismo Jurídico pero, particularmente, pretenden avanzar hacia una reconceptualización neoliberal del derecho o, más bien, hacia una anticipación teórica y conceptual que se adapte mas a las exigencias de la justicia neoliberal en tiempos de globalización o multiculturalidad. No en vano hoy en pleno siglo XXI, en nuestro paulatino abandono del fordismo, oímos con mucha fuerza y convicción sobre el tema del gobierno de los jueces y la justicia de la opinión pública, la justicia mediática, la de la era de la informatización.

\section{Las Funciones del Derecho dentro de la Transición Fordista.}

Hemos señalado más arriba como los trabajos de H. Kelsen y M. Weber pueden ser leídos en la misma clave. El primero construyó las bases para el positivismo jurídico moderno (Bobbio, 1998) y el orden constitucional e internacional del fordismo; el segundo, visualizó en el derecho una herramienta muy importante de racionalización de la acción social que no solo permitía borrar toda huella del derecho natural sino 
que permitía colaborar en el proyecto del capitalismo emergente hacia la burocratización total del orden social, el papel del Estado en su comando y gracias a la desacralización de las concepciones del mundo avanzar en la constitución de los procesos de legitimación racional legal como formas de racionalidad y racionalización que brindaran a la "espiritualidad" del capital mecanismos idóneos de subordinación y control de la población a su proyecto.

En este acápite pretendemos presentar de manera sucinta y hasta esquemática la posición teórica de Weber con relación al Derecho, buscando sugerir un puente con la juridización Fordista que se impulsó en todos los ordenes de la vida pero que al parecer todavía pretende seguir existiendo como vigente en el nuevo pasaje hacia el posfordismo.

Por el momento, quisiéramos tan solo introducirnos en su presentación para insinuar algunas conexiones internas que puede tener esta conceptualización con las consideraciones neoliberales y neoinstitucionales respecto a las funciones del derecho.

\section{Max Weber y la Función del Derecho.}

Es muy conocido y difundido el trabajo de Weber sobre el papel de las religiones en el desarrollo del capitalismo. Estamos hablando de su texto de la Ética Protestante y el Espíritu del Capitalismo. Allí establece una asociación muy estrecha entre la reforma protestante y el crecimiento económico. Nos señala como los principios que animaron a la reforma de ahorro, abstinencia, predestinación, ética por el trabajo, etc. fueron las bases de una identidad colectiva, de un espíritu social que contribuyó o determinó crear una identidad social, individual y colectiva, que se enraizó con los postulados y necesidades del capitalismo naciente en el mundo. Muchos autores señalan que las predicciones de Weber se han cumplido en la medida en que solo basta constatar que en los países en donde la reforma se asentó surgió con fuerza el capitalismo, el espíritu empresarial, la capacidad de ahorro y demás requisitos del capitalismo naciente o de competencia perfecta.

Sin duda, hoy por hoy, con el advenimiento de un capitalismo industrial se rompieron los principios anteriormente mencionados como fueron los de la vida austera y la ética del trabajo. Con la sociedad de masas y del consumo asistimos a un proceso si 
bien sí de secularización de la vida, también a un desarrollo desmedido de la despersonalización de las relaciones sociales y a un deterioro de la ética del trabajo. Se transitó hacia una sociedad consumista y hedonista, en donde la base de la libertad y la igualdad se sustentaron y sustentan en la producción u adquisición del placer como parte de los objetivos sociales y de la vida individual y colectiva. Es posible que estos cambios igualmente han sido producidos por las transformaciones de las relaciones sociales en donde la base del proceso de trabajo se fundamenta en la empresa Fordista, caracterizada por la masificación, estandarización y serialización de la producción.

Siendo así las cosas podemos afirmar que el éxito ya no estaría centrado en los principios desarrollados por la ética de la reforma protestante sino por la individualización y despersonalización de las relaciones sociales, por su carácter anónimo de las mismas, por la capacidad de dar placer y poder a los sujetos, al despilfarro y al consumo inmediato.

Sin embargo, podemos señalar que esas no fueron las únicas inquietudes de Weber. En Economía y Sociedad se ocupa muy profundamente de otros temas que pretenden dar cuenta de las características de la sociedad emergente, particularmente del papel del derecho y las instituciones que de manera laxa podríamos señalar las siguientes, a saber:

a. Una de las características básicas de la sociedad moderna es su naturaleza de producir un tipo ideal de racionalidad, tanto material como formal. Esto lo llevo a estudiar las formas de la racionalidad de la acción social que las destacó como la relación existente entre medios y fines, como la acción racional entre medios y fines. La racionalidad son formas ideales y lógicas del comportamiento humano. Existen formas variadas de obtener esa racionalidad de la acción social median la racionalización de la misma. Esta racionalización apela o se refiere a procedimientos o lógicas de la acción social, individual y colectiva.

b. La racionalidad también puede verse en Weber como formas que la sociedad impone para lograr obediencia y control social de sus acciones. Por tal motivo, él estudia las formas de dominación social que no son más que los mecanismos por medio de los cuales una sociedad logra niveles de control de sus acciones. 
Estableció tres niveles históricos de esas formas de dominación: La tradicional, la carismática y la legal racional.

c. La dominación legal racional la establece o se consigue mediante la organización de un sistema legal racional formal. En este sentido, Weber nos va a senalar que dentro del capitalismo existe tres formas básicas de racionalización: La contabilidad, la administración y el Derecho.

d. El derecho lo entiende como un mecanismo de coerción física, es una técnica de control social.

e. Así las cosas el derecho, como tipo ideal, tiene cuatro formas de existencia: El irracional material (decisiones éticas o morales de naturaleza subjetiva que se toman por fuera del sistema legal), el irracional formal (decisiones previas pero apelando a oráculos, etc.), el derecho racional material (las decisiones son internas al sistema legal pero son impredecibles) y finalmente el derecho racional formal (decisiones lógicas dentro del sistema legal).

f. Weber privilegia el derecho racional formal y en términos de los juristas se podría decir que sería partidario de la dogmática y el formalismo legal. Siendo así las cosas, para Weber el derecho racional formal ha contribuido esencialmente a la predecibilidad de la acción social. Es decir, que haya posibilidad de que la acción racional de medios con respecto a fines pueda cumplirse. De allí que una de las funciones del derecho es la racionalización de la acción social que permite mediante la predecibilidad de la acción generar formas de control social necesarias para la vida social.

g. El fin último para Weber es la consecución de una sociedad altamente racional y no religiosa. Por eso, él advierte la muerte de la vida basada sobre principios religiosos y el florecimiento de los máximos márgenes de racionalización formal de la sociedad. Esta forma social va a desencadenar en la burocratización de la sociedad (no solamente del Estado sino de la empresa), en donde todas las decisiones se comporten con las características del tipo racional legal. El derecho sería la expresión o forma de actuar de la burocratización. De la misma forma, el sistema legal sería la expresión de un cuerpo especializado, altamente 
calificado y que generaría el sistema de normas racionales que orientarían la acción social. El derecho como base de la racionalización y de las formas de la dominación legal racional.

h. Aunque Weber estudio básicamente el capitalismo de competencia perfecta pudo visualizar la tendencia de este, en el sentido de desencadenar los efectos máximos del orden de la racionalización. En estos términos, presagió el papel del derecho dentro del desarrollo capitalista como pieza angular al fenómeno de las formas de dominación contemporáneas y de los mecanismos mas adecuados para cumplir con las metas de la acción racional: el derecho racional formal y la burocratización. Es así que se coloca como uno de los precursores del neoinstitucionalismo, al develar el carácter del derecho dentro del desarrollo y crecimiento de las sociedades.

\section{Una lectura crítica.}

Ahora bien, es necesario a partir de aquí pensar más crítica y detenidamente la relación entre derecho y desarrollo económico, tal como nos lo sugieren los neoinstitucionalistas para efectos de comprender de mejor forma el carácter y naturaleza del derecho y sus instituciones dentro de la sociedad.

De manera preliminar, podríamos hacer las siguientes apreciaciones, a saber:

- En realidad los postulados neoinstitucionales conciben la estructura jurídica como un espacio relativamente autónomo e independiente del mundo económico pero íntimamente interrelacionado. La economía está regulada por una dinámica y leyes propias a su objeto que guardan distancia y tienen plena autonomía del sistema legal. La economía es un mundo auto céntrico y autoreferente que encuentra su dinamismo en la acción de los productores y en la red de relaciones que establecen los oferentes y demandantes de mercancías. El derecho constituye una realidad de naturaleza similar que se comunica como un subsistema (en los términos de Niklas Luhmann) y que cuya función es la de generar el marco general, el contexto dentro del cual se desarrollan los acuerdos y contratos. Se podría decir que frente al mundo de la realidad económica el derecho se encuentra en un lugar periférico. 
- La visión clásica y neoliberal del modelo económico se fundamenta en que como sistema tiene la capacidad de crecer y expandirse de manera ilimitada gracias a la dinámica inherente o propia contenida en su propia lógica de funcionamiento. De allí que unos de los postulados básicos del modelo es que existe plena correspondencia entre oferta y demanda. Todo lo que se produce se consume, todo lo que se ofrece se demanda. De ahí, las tesis de la denominada ley de Say. Adicionalmente, este modelo está ausente de contradicciones. Su dinamismo no se basa en las contradicciones del sistema económico, sino en leyes de la producción y en la ley del valor. El sistema legal igualmente es autoreferente y autopoiético, en el sentido en que tiene capacidad de crecimiento y regulación interna gracias a su racionalidad formal de corte Kelseniano, positivista, dogmático y formalista.

- La habilidad de North fue la de haber encontrado uno de los elementos fundamentales de la relación interna entre estos dos subsistemas. El derecho si bien no produce valor tiene la condición de generar un espacio de seguridad y confianza para la vida de los negocios que muchas veces estos no poseen. Gracias a su naturaleza de técnica de control social o de ser monopolio legítimo de la violencia (como nos lo recuerda Weber) permita que los procesos de racionalización social sean posibles o por lo menos duraderos. De esta medida, se establece un sistema de cooperación entre los distintos actores de la sociedad necesaria para que las redes y los flujos del trabajo puedan ser generados.

- La cooperación que produce el derecho o su estabilidad al sistema económico se puede constituir en un valioso activo que North intentó medir. Aquí estamos refiriéndonos a los llamados Costos de Transacción, que no son otra cosa que la expresión de las condiciones de seguridad de la cooperación interinstitucional necesarias para el funcionamiento de las empresas. La red de proveedores, las estructuras de comunicación con los clientes, la generación y efectividad de los contratos, la responsabilidad en los suministros a tiempo, la velocidad en la distribución de los productos, etc. constituyen por decirlo de alguna forma ahorros importantes en la reducción de los costos de producción de las mercancías y un ahorro importante en la rotación del capital. El tiempo en que el capital está ocioso repercute negativamente en los costos y, por ende, en la capacidad de las empresas de imponer precios de mercado competitivos. 
- El derecho no es considerada propiamente una variable económica. Pero tiene impacto significativo en el sistema económico. La garantía y protección de la propiedad privada, el cumplimiento de los contratos, el buen funcionamiento del sistema judicial, entre otros constituyen las condiciones generales básicas para el buen funcionamiento del sistema económico. Se podría decir que la normalidad jurídica institucional y por qué no decirlo, la vigencia y realización de los principios de la democracia son base del éxito empresarial y de las empresas. Milton Friedman trabajo y construyó una asociación inversa. Para él, la condición básica para obtener democracia, libertad política, etc. es la presencia y vigencia de la libertad económica. La libertad económica, su funcionamiento y dinámica constituyen la conditio sine qua non para la libertad política, para la libertad de elegir. El neoliberalismo ve el impacto de la normalidad económica sobre la normalidad política. El neoinstitucionalismo ve el impacto de la normalidad jurídico política sobre el éxito y buen desempeño de la actividad económica.

Ahora bien, con relación a las posibles respuestas de la Teoría Crítica frente a los desarrollos precedentes es posible presentar anticipada y brevemente algunas de sus reacciones, particularmente frente a la relación entre derecho y desarrollo económico de la siguiente manera, a saber:

- La Teoría Crítica (Pashukanis, 1976) no entiende que el derecho sea una realidad separada y autónoma del mundo económico. De la misma manera, no entiende el mundo económico separado e independiente del mundo jurídico. En realidad, no comparte cierto estructuralismo funcionalista de corte Parsoniano sino, por el contrario, comprende el mundo de la realidad social, y dentro de él el de la producción, como una totalidad. El derecho es concebido como una relación social de producción que constituye y permite el accionar del mundo separado entre la esfera de la circulación y la esfera de la producción. La primera es el reino de la libertad y la igualdad, tanto económica como política, necesarios para el desdoblamiento de la mercancía. La segunda es el reino de la producción inmediata lugar privilegiado de la producción y obtención de valor, del excedente productivo. El derecho no tiene relación de exterioridad con el mundo económico sino que este lo constituye y produce. Tiene la capacidad, mediante el ejercicio de la violencia, física o simbólica, de constituir los agentes o sujetos de la circulación mercantil mediante la constitución 
o apelo a la ciudadanía y sus derechos. El derecho hace posible el trabajo asalariado y el mantenimiento de la propiedad privada. A través de sus mecanismos de ejercicio de la violencia social permite que los dispositivos del poder reproduzcan las relaciones sociales en esas mismas condiciones de exterioridad y extrańeza del sujeto con sus condiciones materiales requieren. De allí que la sociedad moderna solicita para su vigencia y reproducción la existencia del derecho, la juridización de las relaciones sociales en la medida en que éstas no son dadas o naturales sino sociales y expresan un producto social que permanentemente debe ser repuesto.

- El derecho produce las condiciones básicas del mercado. De allí el apelo de North por insistir en la importancia del derecho y sus instituciones en la estabilidad de éste. Los procesos de la racionalidad tanto material como formal de que tanto nos habla Weber se constituyen mediante el apelo a la violencia. Por eso que para él las formas de dominación son o tienen signo positivo, no son cuestionables sino animadas. Sin embargo, la racionalización que produce el derecho, los sistemas de cooperación que éste establece, constituyen tan solo formas históricas nacidas del proceso técnico y social del trabajo pero no constituyen las únicas formas de cooperación de éste en la historia de la producción. Son formas de cooperaciones históricas y socialmente construidas.

- De lo anterior se puede deducir que los llamados subsistemas sociales, como lo son el económico y el jurídico, no son autónomos, a pesar de las múltiples vinculaciones de reciprocidad que se les aducen. También su crecimiento y capacidad auto referente y autopoiético no son ilimitadas sino que ambos "subsistemas" están abocados a llevar la misma suerte. Las crisis de uno constituyen las formas y modalidades de las crisis del otro. Podríamos expresar que no existe para la Teoría Crítica crisis de uno u otro subsistema sino que como totalidad social lo que se presenta en el mundo moderno es crisis de las relaciones sociales de producción.

- Con relación a las virtudes que se aducen del modelo clásico de economía la Teoría crítica ha insistido que se trata de relaciones sociales que entrańan en su seno contradicciones esenciales que le otorgan su dinámica evolutiva. En ese sentido, podemos decir en primer lugar que la pretendida fórmula de equilibrio entre oferta y demanda teórica e históricamente no se ha podido realizar. Ya desde muy temprano se viene advirtiendo que en las sociedades de acumulación ampliada, como lo es la moderna, 
existe un permanente desequilibrio entre ambos términos de la ecuación. Esto conlleva a la imposibilidad de un desarrollo y crecimiento permanente y ad-infinitum. Su evolución se da básicamente como un recorrido que señala permanentes ciclos que expresan tensiones, tendencias y contradentencias que pretenden adecuar o impedir su fractura o resquebrajamiento. Existe una crisis permanente de las relaciones sociales.

Una primera crítica al modelo clásico proviene de las tesis sobre la monopolización de los mercados. A pesar de la existencia de los mercados de competencia perfecta que fijan los precios de equilibrio de conformidad al dinamismo de la oferta y la demanda y la estabilidad que puede suministrarles el recurso de la mano invisible, las diferencias de productividad van señalando diferencias en la composición orgánica del capital que genera necesariamente procesos de sanción de la ley del valor. Las empresas con mayor productividad logran apropiarse cada vez más de sumas adicionales de la ganancia socialmente producida generando un paulatino desarrollo de los procesos de concentración y centralización del capital. Esta circunstancia tiene efectos desintegradores de los mercados de competencia perfecta con la aparición de mercados monopólicos. Los monopolios desnaturalizan el mercado en un doble sentido, a saber: de un lado, por apropiarse de una ganancia extraordinaria por poder establecer sus puntos de equilibrio por debajo de los mercados de competencia perfecta; de otro lado, por fijar ellos de manera autónoma los precios de mercado permitiendo que el mercado y su dinamismo pierdan dicha capacidad. La mano invisible y el mercado pierden su capacidad de asignador de los recursos productivos.

Otra vertiente de la teoría crítica es la formulada por los teóricos circulacionistas (Roldosky, 1978; Grossmann, 1979) que establecen que la crisis del modelo se establece como crisis de realización de las mercancías. De un lado están las contribuciones de Lenin, para quien el desequilibrio entre oferta y demanda es generado por la crisis de sobreproducción de mercancías propia o resultado de la acumulación y valorización de capital. La única manera de solventar esta crisis es mediante la penetración de otros mercados internos para dar salida a la sobreoferta de mercancías. Esta tesis le sirve para plantear sus tesis sobre el imperialismo como respuesta, temporal y transitoria, a la crisis de realización. De otro lado, están las contribuciones de rosa Luxemburgo, para quien la crisis del modelo es igualmente de realización pero debido a la debilidad del fondo general de salarios. Existe una crisis de subconsumo que no logra establecer el equilibrio entre oferta y demanda. La salida propuesta es la 
necesidad de la sociedad de encontrar en lo que ella denomina el tercer sector nuevos demandantes. Se trata específicamente de las poblaciones no vinculadas al circuito moderno de la economía como es el caso de las producciones no capitalistas.

Por último, están las contribuciones de Marx para quien si bien es cierto que es posible que afloren crisis de realización la verdadera o más protuberante crisis del modelo está en lo que él denominó la ley de la baja tendencial de la tasa de ganancia. El proceso de trabajo tiende cada vez más a elevar la composición orgánica de capital y esta medida trae como consecuencia la sustitución de trabajo vivo por trabajo muerto. La producción social cada vez tiene mayores dificultades para producir nuevo valor. Se presenta una crisis de rentabilidad de la producción en la medida en que para obtener las mismas cantidades de valor la producción debe introducir masas cada vez mayores de capital. Esta situación detiene o retarda la valorización y acumulación ampliada del capital. La producción cada vez más se desvaloriza y el fin último de ésta se pierde en la dinámica de producir sumas cada vez mayores de valor.

\section{Conclusiones.}

De lo anterior podemos señalar como los postulados del modelo clásico han sido cuestionados en el sentido de que no se trata de un sistema lineal y sin contradicciones. El sistema legal y la normalidad de las instituciones, la predecibilidad de la acción del Estado y de los agentes económicos. En otros términos, la capacidad de los costos de transacción pueden servir para morigerar las crisis y ser un paliativo importante para reducir los costos, pero todavía no es suficientemente comprobado su capacidad para contribuir como contradentencia eficaz a la crisis ya sea de monopolización de los mercados, de la crisis de realización de las mercancías o de la baja tendencial de la tasa de ganancia.

Las tesis neoliberales aducen permanentemente que las fallas del mercado están básicamente centradas en la falta de información y comunicación de los agentes económicos. La oportuna y eficaz información puede lograr una asignación más racional de los recursos económicos y permitir que la mano invisible logre cumplir con sus propósitos. La predicibilidad jurídica haría parte de esos sistemas de información oportunos necesarios para que las empresas lograran tener todo el acervo disponible 
para realizar sus inversiones. El neoinstitucionalismo se presenta como un cuerpo teórico coherente a disposición de esas pretensiones del modelo neoliberal. Es posible que esa combinación o matrimonio logre en ciertos momentos generar espacios de crecimiento económico. Los costos de ese crecimiento económico todavía son impredecibles, aunque ya los grupos y comunidades vienen descifrando en carne propia sus secuelas. Se apela hoy en día a la distinción entre crecimiento económico y desarrollo social. Que en términos del derecho puede hacerse la traducción entre derecho formal y derecho material. Tensiones que solo el tiempo nos dirán como se irán resolviendo.

\section{Bibliografía}

Aglietta, M. (1987). Regulación y crisis del capitalismo. México: Ed. Nueva era.

Altamira, C. (s.f.). Trabajo vivo, crisis y nuevos sujetos sociales. . Recuperado el 10 de Abril de 2013, de Rev. Espacio crítico (5) 2006: www.espaciocritico.com.

Bell, D. (1996). Las Contradicciones Culturales del Capitalismo. Madrid: Alianza Universidad. Bobbio, N. (1998). El Positivismo Jurídico. Madrid: Ed. debate.

Boyer, R. (1992). La Teoría de la Regulación: Un Análisis Crítico. Valencia: Ediciones Alfonso el Magnánimo.

Burgos, G. (2006). Crecimiento Económico Sin Estado de Derecho. Bogotá: Universidad Nacional de Colombia.

Burgos, G. (2006i). Instituciones jurídicas y crecimiento económico: la experiencia asiática. Rev. De Economía Institucional. FALTA EL NÚMERO O VOLUMEN.

Castells, M. (1999). La Era de la Información. Madrid: S. XXI.

Coase. (1994). La empresa, el mercado y la ley. Madrid: Alianza.

Coriat, B. (1979). El Taller y el Cronómetro. Ensayo sobre el taylorismo, el fordismo y la producción en masa. México: S. XXI.

Dejorurs, C. (1987). Estudo de Sicopatología Do Trabalho. Sao Paulo: Oboré Editorial.

Dworkin, R. (1989). Los derechos en Serio. Barcelona: Ariel. 
Friedman, M. (1980). La Libertad de elegir. México: Ed. Grijalbo.

Friedman, M. (1985). Capitalismo y Libertad. México: Ed. S. XXI. .

Grossmann, H. (1979). Ensayos sobre la teoría de las crisis. Cuadernos de pasado y presente (79).

Hart, H. (1998). El Concepto de Derecho. Buenos Aires: Abeledo-Perrot.

Hobsbawm, E. (1995). Historia del Siglo XX. Barcelona: Ed. Crítica Grijalbo Mondadori.

Jessop, B. (1999). Crisis del Estado de Bienestar. Bogotá: Siglo del hombre editores.

Kelsen, H. (2005). Teoría Pura del Derecho. Buenos Aires: Eudeba.

Lipietz, A. (1992). Espejismos y milagros. Bogotá: Tercer mundo Editores y Univ. Nacional de Colombia.

Marx, C. (1977). El Capital. Crítica de la Economía Política. Bogotá: FCE.

Meillassoux, C. (1981). Mujeres, graneros y capitales. Bogotá: S. XXI.

Moncayo, V. M. (1990). Sobre la naturaleza del derecho como forma social de la dominación. Rev. Jurisprudencias. No. 32

Moncayo, V. M. (2004). El Leviatán Derrotado. Bogotá: Ed. Norma.

Navarro, V. (1977). Neoliberalismo y Estado del Bienesta. Barcelona: Ariel Sociedad Económica.

North, D. (2001). Instituciones, cambio institucional y desempeño económico. México: FCE.

O’Connor, J. (1981). La Crisis Fiscal del Estado. Barcelona: Peninsula.

Offe C. (1988). Gestión Política. Bogotá, Colombia.: Ministerio del Trabajo y Seguridad Social

Palacio, G. (1993). Pluralismo Jurídico. Bogotá: Universidad Nacional de Colombia. Facultad de Derecho, Ciencias Políticas y Sociales.

Pashukanis, E. (1976). Teoría General del Derecho y el Marxismo. Medellín: Ed. La Pulga.

Rawls, J. (1995). Teoría de la Justicia. Madrid: FCE.

Rodríguez, J. E. (1990). La producción social del derecho. Rev. El Otro Derecho (6). 
Rodríguez, J. E. (1991). Pluralismo Jurídico: El Derecho del Capitalismo Actual? Rev. Nueva Sociedad (112).

Rodríguez, J. E. (1996). Elementos para un estudio crítico de la mujer dentro de la sociedad contemporánea. Rev. El Otro Derecho (7) 3. ILSA.

Rodríguez, J. E. (2002). Procesos de trabajo, valorización y reestructuración del espacio. Bogotá: . Ed. Unibiblios. Universidad Nacional de Colombia.

Rodríguez, J. E. (2008). La Agonía del Estado de Derecho Positivo. Bogotá: Fundación Universidad Autónoma de Colombia.

Rodríguez, J. E. (2012). De Crisis en Crisis: Las Limitaciones de los Cambios en la Justicia en Colombia. Bogotá: Universidad Autónoma de Colombia.

Roldosky, R. (1978). Génesis y Estructura Lógica de El Capital de Marx. México: FCE.

Sousa Santos, B. (1993). O social e o politico na transicao pos-moderna. Lua Nova, 31,181-208

Taylor F. (1970). Management Cientifico. Barcelona, España.: OIKOS-TAU SA

Von Hayek, F. (1986). Caminos de Servidumbre. San José: Universidad Autónoma de Centroamérica.

Weber, M. (1977). Economía y Sociedad. México: FCE.

Weinbaum, B. (1984). El curioso noviazgo entre feminismo y socialismo. Madrid: S. XXI.

Williamson, O. (1989). Las instituciones económicas del capitalismo. . México: FCE. 